\title{
BMJ Global Health Building a new platform to support public health emergency response in Africa: the AFENET Corps of Disease Detectives, 2018-2019
}

\author{
Ben Masiira (D , ${ }^{1}$ Simon N Antara, ${ }^{2}$ Herbert B Kazoora, ${ }^{1}$ Olivia Namusisi, ${ }^{1}$ \\ Notion T Gombe, ${ }^{3}$ Alain N Magazani, ${ }^{4}$ Patrick M Nguku, ${ }^{5}$ Ditu Kazambu, ${ }^{6}$ \\ Sheba N Gitta, ${ }^{1}$ Christine Kihembo, ${ }^{1}$ Bernard Sawadogo, ${ }^{7}$ Tatek A Bogale, ${ }^{8}$ \\ Chima Ohuabunwo, ${ }^{9}$ Peter Nsubuga, ${ }^{10}$ Mufuta Tshimanga ${ }^{11}$
}

\begin{abstract}
To cite: Masiira B, Antara SN, Kazoora HB, et al. Building a new platform to support public health emergency response in Africa: the AFENET Corps of Disease Detectives, 2018-2019. BMJ Global Health 2020;5:e002874. doi:10.1136/ bmjgh-2020-002874
\end{abstract}

Handling editor Seye Abimbola

Received 9 May 2020

Revised 4 September 2020

Accepted 7 September 2020
Check for updates

(c) Author(s) (or their employer(s)) 2020. Re-use permitted under CC BY-NC. No commercial re-use. See rights and permissions. Published by BMJ.

For numbered affiliations see end of article.

Correspondence to

Dr Ben Masiira;

bmasiira@afenet.net

\section{ABSTRACT}

Public health emergency (PHE) response in sub-Saharan Africa is constrained by inadequate skilled public health workforce and underfunding. Since 2005, the African Field Epidemiology Network (AFENET) has been supporting field epidemiology capacity development and innovative strategies are required to use this workforce. In 2018, AFENET launched a continental rapid response team: the AFENET Corps of Disease Detectives (ACoDD). ACoDD comprises field epidemiology graduates and residents and was established to support PHE response. Since 2018, AFENET has deployed the ACODD to support response to several PHEs. The main challenges faced during ACoDD deployments were financing of operations, ACoDD safety and security, resistance to interventions and distrust of the responders by some communities. Our experience during these deployments showed that it was feasible to mobilise and deploy ACoDD within 48 hours. However, the sustainability of deployments will depend on establishing strong linkages with the employers of ACoDD members. PHEs are effectively controlled when there is a fast deployment and strong linkages between the stakeholders. There are ongoing efforts to strengthen PHE preparedness and response in sub-Saharan Africa. ACoDD members are a competent workforce that can effectively augment PHE response. ACoDD teams mentored front-line health workers and community health workers who are critical in PHE response. Public health emergence response in sub-Saharan Africa is constrained by inadequacies in a skilled workforce and underfunding. ACoDD can be utilised to overcome the challenges of accessing a skilled public health workforce. To improve health security in subSaharan Africa, more financing of PHE response is needed.

\section{INTRODUCTION}

The risk that infectious agents will continue to kill humans in the 21st Century is highest in Africa. ${ }^{1}$ According to the WHO, Africa experiences more than 100 disease outbreaks and other health emergencies annually. ${ }^{2}$ From

\section{Summary box}

- Innovative strategies can be applied to leverage the inadequate public health workforce to address public health challenges including emergencies.

- ACoDD was established to support ministries of health to overcome the challenges of rapidly mobilising and deploying adequate and skilled public health workforce.

- Public health emergency response in sub-Saharan Africa is still constrained by underfunding.

- It is feasible to mobilise and deploy ACoDD member within 48 hours to support ministries of health to respond to emergencies.

- Lack of effective community engagement can result into violence against the rapid responders.

- Psychosocial support can be a game changer in addressing difficult situations faced by rapid responders such as distrust.

the beginning of 2020, African countries have been facing one of the greatest challenges: the COVID-19 pandemic. The COVID-19 pandemic started in China in December 2019 and rapidly spread across the globe. Such public health emergencies (PHEs) expose the fragility of emergency response systems in Africa. For example, the Ebola virus disease (EVD) epidemic in West Africa claimed $>11000$ lives and cost billions of US dollars in socioeconomic losses. ${ }^{34}$ For an effective PHE response, the Global Health Security Agenda recommends countries to have at least one field epidemiologist (trained at the advanced or intermediate levels) per 200000 population. ${ }^{5}$ Other authors have suggested a coverage three to five field epidemiologists per million population. ${ }^{6}$ However, data at the African Field Epidemiology Network (AFENET) show that the sub-Saharan region 
has only $33 \%$ of the required number of field epidemiologists.

\section{ACODD CONCEPTION AND INCEPTION}

AFENET was established in 2005 to support field epidemiology workforce development in sub-Saharan Africa. During the Ministerial Round Table meeting held in the 2016 AFENET Conference, the ministers called for innovative strategies of leveraging existing workforce and recommended the establishment of a Continental Rapid Response Corps from existing field epidemiologists. ${ }^{7}$ On 7 May 2018, AFENET Board of Directors launched the AFENET Corps of Disease Detectives (ACoDD). ACoDD is a Rapid Response Team (RRT) which comprises residents and graduates from the 2 years advanced, the 9 months intermediate and the 3 months front-line field epidemiology training programmes (FETPs). The aim of ACoDD is to ensure efficient utilisation of the field epidemiology and laboratory training programmes workforce in response to PHEs. ACoDD was established to overcome the challenges of rapidly mobilising and deploying adequate and skilled workforce within 72 hours for timely response to PHEs.

\section{ACODD DISTRIBUTION, ORGANISATIONAL STRUCTURE AND MANAGEMENT OF OPERATIONS}

Since the inception of FETPs in sub-Saharan Africa, a total of 1995 advanced level and 248 intermediate level field epidemiologists, and 4951 health workers have graduated from the 3 months FETP across the network (figures 1-3).

ACoDD's organisational structure is summarised in figure 4. There are three levels of ACoDD management; the AFENET Secretariat, regional and country levels. At the AFENET Secretariat, the Head of AFENET (who reports to the AFENET Board of Directors) provides overall strategic leadership, the Head of Programmes

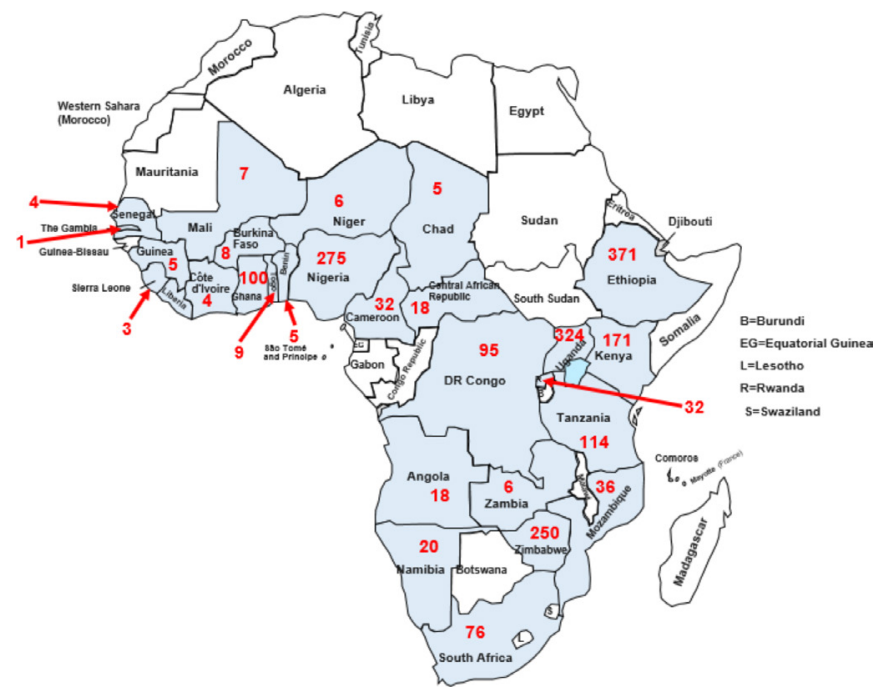

Figure 1 Distribution of advanced field epidemiology graduates.

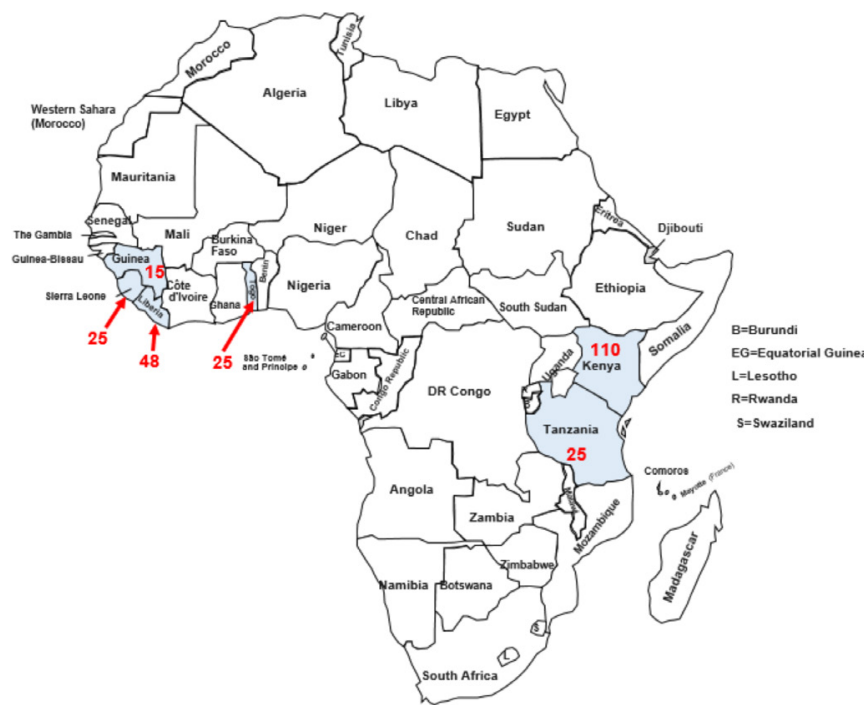

Figure 2 Distribution of intermediate field epidemiology graduates.

provides overall technical leadership and the ACoDD Focal Person (FP) coordinates operations across the network. At regional level, ACoDD operations are led by the AFENET Regional Technical Coordinator (RTC). At country level, the ACoDD operations are led by the country FP who is the FETP Resident Advisor. Details of the ACoDD management team responsibilities are summarised in table 1 .

\section{KEY ACODD DEPLOYMENTS DURING PUBLIC HEALTH EEMERGENCY RESPONSE IN SUB-SAHARAN AFRICA, 2018- 2020}

ACoDD has supported response to several emergencies including disease outbreaks, mass gathering event-based surveillance, polio surveillance and natural disasters such as Cyclone Idai in the southern Africa region. Outlined below are the key disease outbreaks where ACoDD members were deployed.

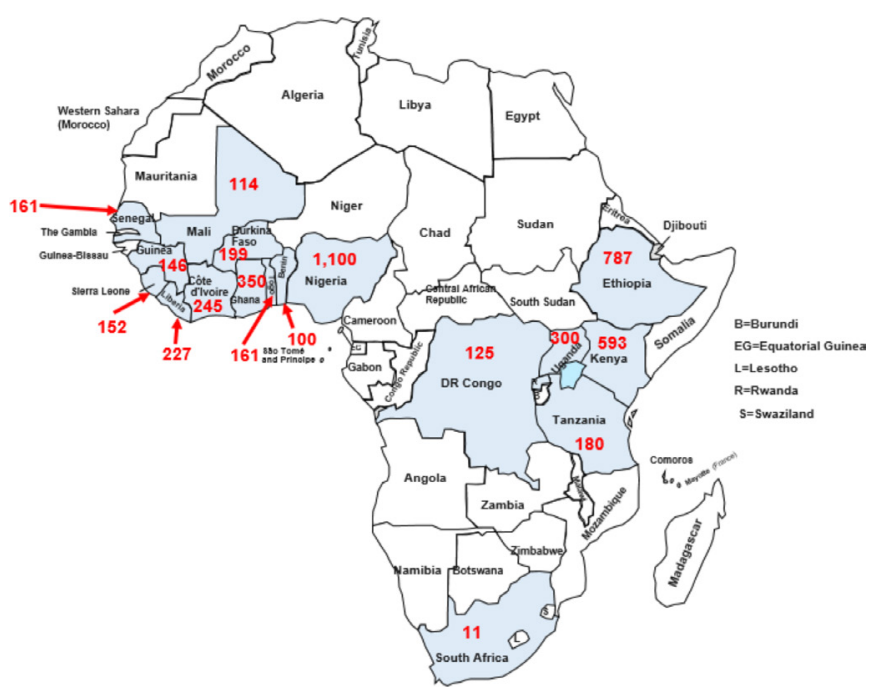

Figure 3 Distribution of front-line field epidemiology graduates. 


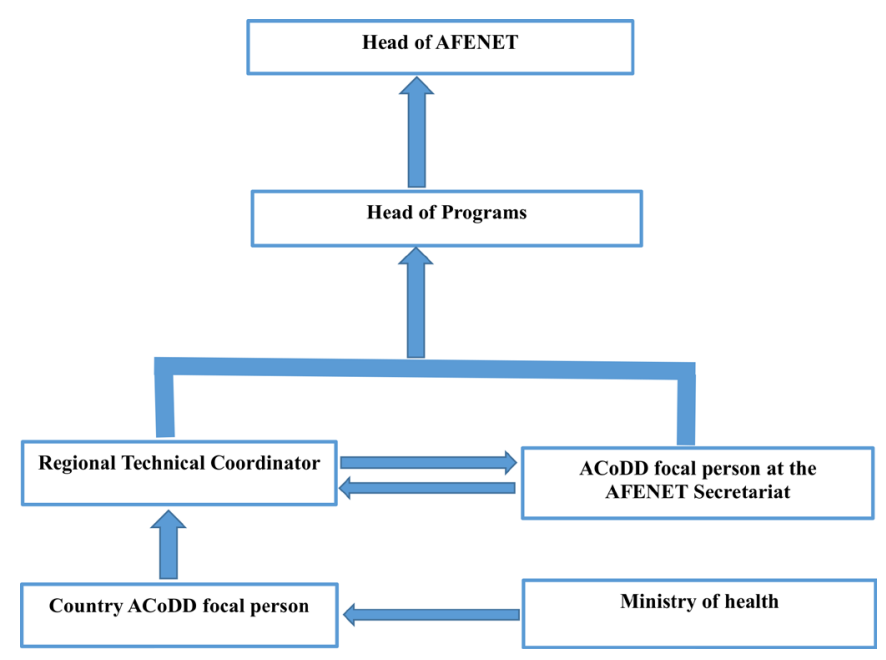

Figure 4 Organisation and coordination of ACoDD operations. ACoDD, AFENET Corps of Disease Detectives; AFENET, African Field Epidemiology Network.

\section{The ninth Ebola virus disease outbreak in the Democratic Republic of the Congo, May-July 2018}

Soon after ACoDD was launched, AFENET received a request from the DRC Ministry of Health to support the response to the EVD outbreak in Équateur Province. This EVD outbreak had been declared on 8 May 2018. Between 10 May and 24 July 2018, AFENET, in collaboration with the US Centres for Disease Control and Prevention (CDC), deployed a team of 84 ACoDD members to support the national RRT contributing a total of 2590 person-days of deployment. ACoDD members investigated 432 alerts of which 22 were confirmed with EVD, identified 1319 contacts of which 939 were followed up, mentored 1036 front-line health workers and conducted a total of 2579 community sensitisation sessions. Other ACoDD members were involved in screening of 15650 passengers at five priority points of entry (PoEs) and points of control (PoCs) to identify suspected cases of EVD surveillance. The ACoDD conducted data analysis and compiled and presented 60 daily updates that helped inform the outbreak response strategies.

This outbreak was quickly contained and the Minister of Health announced its end on 24 July 2018. ${ }^{8}$ The outbreak had a total of $54 \mathrm{EVD}$ cases of which 38 were confirmed, 16 were probable, 33 died (case fatality ratio: $61 \%)$. Of the 51 cases, 21 occurred in Bikoro health zone, 29 occurred in Iboko health zone and 4 occurred in Wangata health zone. ${ }^{8}$

\section{Cholera outbreak in Harare City, Zimbabwe, September- November 2018}

On 6 September 2018, the Ministry of Health and Child Care (MoHCC) of Zimbabwe declared a cholera outbreak in Harare City following confirmation of Vibrio cholerae serotype O1 Ogawa among initial patients with symptoms consistent with cholera. On the request of MoHCC, AFENET deployed 20 ACoDD in different outbreak hotspots on 18 September 2018, contributing a total of 1200 person-days to the response.

As part of the MoHCC RRT, ACoDD teams investigated 1400 cholera cases, identified 145 cases through active cholera case search and participated in outbreak data analysis. ACoDD members with clinical background supported case management teams at health facilities and assessed compliance to treatment protocols by case management teams. A team of ACoDD participated in conducting risk communication, community

\begin{tabular}{|c|c|}
\hline Office & Roles and responsibilities \\
\hline Director of AFENET & $\begin{array}{l}\text { Provides overall strategic leadership of the ACoDD operations } \\
\text { Leads advocacy } \\
\text { Resource mobilisation }\end{array}$ \\
\hline Director of Programmes & $\begin{array}{l}\text { Overall technical oversight for the ACoDD operations } \\
\text { Resource mobilisation } \\
\text { Approval of budgets for operations }\end{array}$ \\
\hline Secretariat Focal Person & $\begin{array}{l}\text { Coordinates mobilisation of ACoDD across the network } \\
\text { Provision of technical support and supervision of ACoDD teams during deployment } \\
\text { Maintains a database (Epi-Track) of ACoDD across the network }\end{array}$ \\
\hline Regional Technical Coordinators & $\begin{array}{l}\text { Engaging ministries of health and partners to release ACoDD members for deployment } \\
\text { Resource mobilisation to support operations } \\
\text { - Providing technical support and supervision of ACoDD teams during deployment } \\
\text { - Maintain a database for the ACoDD at (Epi-Track) at the regional level }\end{array}$ \\
\hline Country ACoDD Focal Person & $\begin{array}{l}\text { Receive requests for support from the ministries of health } \\
\text { Planning and budgeting for deployment } \\
\text { Mobilisation of ACoDD at country level } \\
\text { Coordinating predeployment briefing and orientation } \\
\text { Providing daily situation updates during an outbreak response } \\
\text { Maintains a database for the ACoDD at (Epi-Track) at country level }\end{array}$ \\
\hline
\end{tabular}

ACoDD, AFENET Corps of Disease Detectives; AFENET, African Field Epidemiology Network. 
engagement and social mobilisation. ACoDD teams also conducted environmental assessments including water testing. This epidemic was eventually controlled with the last case reported on 11 December 2018. ${ }^{9-11}$ This outbreak affected a total of 9949 individuals of which 55 died (case fatality ratio, $\mathrm{CFR}=0.5 \%)$ of which $4457(45 \%)$ were from Glen View suburb and 2869 (29\%) from Budiriro suburb. ${ }^{10}$

\section{The sixth Ebola virus disease outbreak in Uganda, June-July 2019}

This EVD outbreak was declared by the Ministry of Health on 11 June 2019. On 12 June 2019, AFENET received a request to support the response. The index case was a 5-year-old boy who travelled to Uganda with six other individuals who were being monitored as contacts to a confirmed EVD case in DRC. He tested positive for Ebola Zaire by reverse transcription polymerase chain reaction test after presenting at Bwera Ebola Treatment Unit (ETU), Kasese District, with symptoms consistent with EVD.

A total of 15 ACoDD members were deployed in rotations for 30 days contributing a total of 450 person-days. Once in the field, ACoDD members had a meeting with the field incident commander and the district health leadership to get an understanding of the outbreak and to finalise the terms of reference. ACoDD teams investigated 381 alerts none of which was confirmed with EVD and listed 151 contacts of which 142 (94\%) were followed up and tested negative after completing the follow-up period. The ACoDD reviewed 21704 medical records at 30 health facilities to identify suspected EVD cases and out of these records nine suspected cases were identified and all tested negative for EVD. In addition, the ACoDD screened 5080 travellers at PoEs, participated in community-based and event-based surveillance, community sensitisation, psychosocial support and data analysis.

The response team initially found surveillance and contact tracing difficult due to community mistrust and false information. For example, there was information that suspected patients with Ebola admitted to the ETU and their contacts are killed by a 'lethal injection' in order to prevent further transmission of EVD. These rumours made one of the high-risk contacts to go into hiding. When the high-risk contact was traced in one of the remote locations, he rejected Ebola vaccination despite several visits by the teams. However, after 3 days of counselling by the psychosocial team, the high-risk contact eventually accepted EVD vaccination.

Because of the community mistrust and misinformation, the RRT adopted a community-led surveillance and contact tracing strategy. Under this approach, community health workers known as village health teams (VHTs) were trained. The VHTs conducted contact tracing under the close supervision from the contact tracing teams. During field activities, ACoDD teams mentored 201 health workers and 856 VHTs. This EVD outbreak involved three confirmed cases, all of whom died (case fatality ratio, CFR: 100\%) and all had an epidemiological link to a confirmed case who died in DRC.

\section{The tenth Ebola virus disease outbreak in Democratic Republicof the Congo, August 2018-1 March 2020}

The government of DRC declared the tenth outbreak of EVD in North Kivu Province on 1 August 2018 which spread rapidly to other provinces. On 12 August 2018, the ACoDD FP received a request for support from the Ministry of Health. Between 16 August 2018 and 1 March 2020, AFENET deployed a total of 70 ACoDD members (on rotation basis) in various outbreak hotspots and contributed a total of 6000 person-days to this response. ACoDD members investigated 17508 alerts of which 211 were confirmed with EVD, followed up 14708 contacts of confirmed EVD cases of which 179 tested positive for EVD. The teams also mentored 2054 front-line health workers on surveillance and conducted 50282 community sensitisation sessions. Other ACoDD members were involved in infection prevention and control (IPC) and screening at PoE and PoC and health education of EVD and data analysis.

Many of the ACoDD teams faced community resistance and constant security challenges, amidst the increase in the spread of the outbreak, which had a negative impact on the response. On 17 July 2019, WHO declared this outbreak as a Public Health Emergency of International Concern. AFENET received grants from the US CDC and the World Bank to enhance response efforts. These funds were used to implement Surveillance Training to Enhance Ebola Response and Readiness (STEER) for the front-line health workers, community health workers and ACoDD deployment. STEER focused on building the capacity in EVD surveillance, IPC and risk communication. A total of 2047 health workers and 5107 community health workers in EVD affected health areas were trained.

By December 2019, the RRTs were starting to register success with 10 new EVD cases reported during the week of November 25 to 1 December 2019 compared with 39 cases during the week of 16-22 September 2019. ${ }^{12} 13$ By 1 March 2020, there was no new confirmed EVD case since 24 February 2020, and a total of 3444 EVD cases had been reported of which 3310 were confirmed cases, 134 probable cases and 2264 cases had died (case fatality ratio of $66 \%) .{ }^{14}$ As of 1 March 2020, there were signs that the epidemic had been contained with the last cases all reported from a small geographical area within Beni health zone.

\section{ACoDD response to the COVID-19 pandemic}

As soon as the Chinese government declared the COVID-19 outbreak, countries on the African continent activated their emergency preparedness and response mechanisms. By 30 January 2020, WHO declared the pandemic a PHE of global emergency of international concern. In early February 2020, the ACoDD FPs started working with AFENET to mobilise ACoDD members to be on stand-by to support ministries of health and technical 
agencies/networks such as the WHO, US CDC, Global Outbreak Alert and Response Network and Africa CDC.

ACoDD teams across AFENET member countries supported various activities including (1) coordination and planning, (2) development of the national response plans, (3) adapting the WHO COVID-19 case definition to country contexts, (4) investigation of suspected cases, (5) PoE screening, (6) contact tracing, (7) training of RRTs and screeners at PoEs, (8) risk communication and (9) supporting the development of protocols and Standard Operating Procedures (SOPs).

AFENET supported Africa CDC to recruit ACoDD epidemiologists to strengthen COVID-19 capabilities among African countries. These volunteers supported coordination and planning, building capacities for surveillance, laboratory, IPC and case management, policy development and provided technical support to Public Health Emergency Operation Centres to develop incident action plans and SOPs.

\section{CHALLENGES}

ACoDD teams faced four key challenges during deployment and these are highlighted below.

\section{Financing of the ACoDD operations}

The bulk of AFENET operations are supported by the US CDC and the United States Agency for International Development. Between August 2018 and March 2020, AFENET received 39 requests for ACoDD support from member countries of which $15(38 \%)$ were funded. ACoDD deployments were largely supported using the funds generated from indirect project costs while some deployments received direct support from the US CDC. Although AFENET uses a cost-effective model for ACoDD deployment, available funding has been insufficient to meet the growing demand for ACoDD support. A more sustainable strategy for funding of PHE response should be led by the African governments. However, investigations have shown that the majority of countries in Africa allocate below $10 \%$ of their total budget to the health sector. $^{1516}$

\section{Availability of ACoDD for deployment}

Because majority of ACoDD are not employed by AFENET, their availability to support PHE response depends on their release by employers. During deployments, some of the ACoDD members could only serve a short duration in the field which presented a challenge of recruiting and orientation of new volunteers. Although AFENET has been able to mobilise adequate numbers of ACoDD members during emergencies, mobilisation is anticipated to be difficult in large-scale PHEs which require a bigger workforce.

\section{Safety and security during deployment}

The safety of RRTs is one of the critical elements for an effective response. Overall, ACoDD and other responders operated in a safe and secure environment in most of the deployments. However, the response to the EVD outbreak in DRC was substantially hampered by insecurity. ACoDD teams in insecure areas always operated in constant fear of being attacked by the armed groups. On 19 April 2019, a doctor who was deployed by WHO was brutally murdered at the Butembo University Hospital. ${ }^{17}$ On the night of 28 November 2019, armed rebel forces attacked a camp at Biakato Mines and killed four health workers. ${ }^{18}$ The deteriorating security situation led to the evacuation of several RRT members, including 15 ACoDD members, to Goma City on 2 December 2019.

\section{Resistance to interventions and distrust of the responders}

Although the ACoDD participated in community sensitisation during the tenth EVD outbreak in DRC and the sixth EVD outbreak in Uganda, community resistance and distrust remained a key challenge. In both outbreaks, lack of trust was primarily driven by false information, misperceptions and ignorance about control strategies. Whereas in Uganda the distrust was easily controlled through community engagement, the responders in DRC faced a more complex situation. A mob attacked one of the ETUs in DRC resulting into patients and caregivers fleeing and one of the caregivers was killed. ${ }^{19}$ Activities such as identification of new cases and safe, dignified burials were dangerous to implement in some areas because of violence from the residents. ${ }^{20} \mathrm{Commu}$ nity resistance and distrust was also documented during the response to the West Africa EVD outbreak. ${ }^{21}{ }^{22}$

\section{LESSONS LEARNED}

Although FETPs started over two decades ago in subSaharan Africa, ${ }^{23}$ the region is still faced with a scarcity of field epidemiologists. During ACoDD launch, the participants were engaged in discussions about the anticipated challenges related to ACoDD deployment. The key anticipated challenges elicited from participants included difficulty in mobilising adequate numbers of ACoDD members, lack of interest in responding to outbreaks due to highly infectious pathogens such as EVD, and delays or non-release of the ACoDD members by their employers.

Our experience showed that its feasible to mobilise and deploy adequate numbers of ACoDD members within 48 hours after receiving requests from ministries of health. Many ACoDD members felt motivated to participate in rapid response within their countries and beyond. The ACoDD members employed within government ministries were easily released compared with those in the private health sector.

All ACoDD deployments were approved and effected by the ministries of health. Before field deployment, predeployment briefings were conducted with a special focus on discussing the terms of reference. ACoDD members were integrated into the national RRT and their daily operations were under the direct supervision of ministries of health. 
Although the deployments were largely successful, sustainability will rely on establishing strong linkages with organisations that employ the ACoDD members. AFENET is continuously sensitising and engaging the organisations that employ the ACoDD members to ensure that they release them during emergencies. The final key lesson learnt was that PHEs were effectively controlled when the responders were rapidly deployed and when there was strong collaboration between the key stakeholders. An analysis of the EVD outbreak in West Africa showed that a well-coordinated faster response would have halted the propagation of the outbreak. ${ }^{24}$

\section{OPPORTUNITIES}

Considerable efforts are ongoing in the sub-Saharan Africa region to strengthen preparedness and response to PHEs. From its founding in 2005 AFENET, in collaboration with the US CDC, universities and other technical partners, has been contributing to health systems strengthening. ACoDD members are a skilled workforce that can be utilised to support emergency response. The AFENET cost-effective strategy for ACoDD deployment is centred on in-country field epidemiologists; with recruitment from other countries only done once the in-country ACoDD have been exhausted. The recruitment strategy provides an added advantage in that the ACoDD members are well versed with the country context and can easily communicate to the target populations as opposed to recruiting external ACoDD members. During deployments, ACoDD teams interacted, worked with and learnt from other experienced responders. Furthermore, in areas where the ACoDD members were deployed, they were involved in mentoring the front-line health workers and community health workers.

\section{CONCLUSION}

Effective public health preparedness and response in sub-Saharan Africa is constrained by inadequate skilled human resources and underfunding. The ACoDD platform is AFENET's innovative strategy to deploy the existing field epidemiology workforce to support PHE response. Experience from these deployments has shown that the ACoDD can be rapidly mobilised and deployed to the field. The contributions of the ACoDD since its establishment is a clear demonstration of leveraging the existing workforce to solve the complex public health challenges that threaten health security in sub-Saharan Africa. The deficiencies in financing the health sector in sub-Saharan Africa emphasise the need for African governments to devote more financial support and resources for PHE response.
${ }^{4}$ Programs, African Field Epidemiology Network, Kinshasa, Congo (the Democratic Republic of the)

${ }^{5}$ African Field Epidemiology Network, Abuja, Nigeria

${ }^{6}$ African Field Epidemiology Network, Kinshasa, Congo (the Democratic Republic of the)

${ }^{7}$ African Field Epidemiology Network, Ouagadougou, Burkina Faso

${ }^{8}$ Programs, African Field Epidemiology Network, Addis Ababa, Ethiopia

${ }^{9}$ African Field Epidemiology Network, Kampala, Uganda

${ }^{10} \mathrm{Global}$ Public Health Solutions, Atlanta, Georgia, USA

${ }^{11}$ African Field Epidemiology Network, Harare, Zimbabwe

Twitter Notion T Gombe @gombent

Contributors BM participated in conception of the manuscript, supervision of ACoDD deployments, synthesis of field experiences and writing all the drafts of the manuscript. SA participated in conception of the study, supervision of deployments, writing and reviewing of the manuscript and approval of the manuscript. HBK participated in conception and supported manuscript writing at all stages. ON wrote the field experiences from the Uganda ACoDD deployment and participated in reviewing and writing of the manuscript at all stages. NTG wrote the field experiences from Zimbabwe, supervised ACoDD deployment and participated in writing of the manuscript at all stages. ANM wrote the field experiences from DRC ACoDD deployments and participated in writing of the manuscript at all stages. PMN participated in writing and reviewing of the manuscript at all stages. DK wrote supervised ACoDD deployment in DRC and participated in writing of the manuscript at all stages. SNG, CK, BS and ATB participated in writing and reviewing of the manuscript at all stages. $\mathrm{CO}$ participated in conception of the study, supervision deployments and reviewing of the manuscript. PN participated in study conception, writing and reviewing of the manuscript at all stages. MT participated in conception of the study, supervision deployments, writing and reviewing of the manuscript and gave final approval of the manuscript.

Funding The authors have not declared a specific grant for this research from any funding agency in the public, commercial or not-for-profit sectors.

Competing interests None declared.

Patient consent for publication Not required.

Provenance and peer review Not commissioned; externally peer reviewed.

Data availability statement № data are available.

Open access This is an open access article distributed in accordance with the Creative Commons Attribution Non Commercial (CC BY-NC 4.0) license, which permits others to distribute, remix, adapt, build upon this work non-commercially, and license their derivative works on different terms, provided the original work is properly cited, appropriate credit is given, any changes made indicated, and the use is non-commercial. See: http://creativecommons.org/licenses/by-nc/4.0/.

\section{ORCID iD}

Ben Masiira http://orcid.org/0000-0002-7367-065X

\section{REFERENCES}

1 Fenollar F, Mediannikov O. Emerging infectious diseases in Africa in the 21st century. New Microbes New Infect 2018;26:S10-18.

2 World Health Organization. WHO health emergencies programme in the African region: annual report 20162017.

3 WHO. Ebola Situation Report - 30 March, 2016. Available: http:// apps.who.int/ebola/current-situation/ebola-situation-report-30march-2016 [Accessed 28 Jan 2019].

4 Huber C, Finelli L, Stevens W. The economic and social burden of the 2014 Ebola outbreak in West Africa. $J$ Infect Dis 2018;218:S698-704.

5 CDC. Global health security agenda: GHSA workforce development action package (GHSA action package Detect-5). Available: https:// www.cdc.gov/globalhealth/security/actionpackages/workforce development/

6 Nsubuga P, Nwanyanwu O, Nkengasong JN, et al. Strengthening public health surveillance and response using the health systems strengthening agenda in developing countries. BMC Public Health 2010;10 Suppl 1:S5.

7 AFENET. Ministerial resolutions on African field epidemiology network (AFENET), Abuja 2016, 2016. Available: http://afenet.net/ index.php/about-us/annual-reports-3/377-annual-report-2017 
8 WHO. Ebola virus disease - Democratic Republic of the Congo. Available: http://www.who.int/csr/don/25-july-2018-ebola-drc/en/ [Accessed 22 Oct 2019].

9 Regional Office for Africa. Outbreaks and Emergencies Bulletin, Week 01: 29 December 2018 - 04 January 2019. Available: https:// www.afro.who.int/fr/node/10779 [Accessed 25 Nov 2019].

$10 \mathrm{WHO}$, Regional Office for Africa. Outbreaks and Emergencies Bulletin, Week 51: 15 - 21 December 2018. Available: https://www. afro.who.int/publications/outbreaks-and-emergencies-bulletin-week51-15-21-december-2018 [Accessed 25 Nov 2019].

$11 \mathrm{WHO}$, Regional Office for Africa. Outbreaks and Emergencies Bulletin, Week 52: 22 - 28 December 2018. Available: https://www. afro.who.int/publications/outbreaks-and-emergencies-bulletin-week52-22-28-december-2018-0 [Accessed 25 Nov 2019].

12 ReliefWeb, Democratic Republic of the Congo. Democratic Republic of Congo: Ebola Virus Disease - External Situation Report 70. Available: https://reliefweb.int/report/democratic-republic-congo/ democratic-republic-congo-ebola-virus-disease-external-situation85 [Accessed 4 Dec 2019].

13 WHO. Ebola virus disease Democratic Republic of Congo: external situation report 60/2019. Available: https://www.who.int/ publications-detail/ebola-virus-disease-democratic-republic-ofcongo-external-situation-report-60-2019 [Accessed 4 Dec 2019].

14 WHO. Ebola virus disease. Democratic Republic of the Congo. external situation report 82 . Available: https://apps.who.int/iris/ bitstream/handle/10665/331307/SITREP_EVD_DRC_20200303-eng. pdf
15 Mclntyre D, Gilson L, Mutyambizi V. Promoting equitable health care financing in the African context: current challenges and future prospects 2005.

16 World Health Organization. State of health financing in the African region 2013.

17 WHO. Ebola Responder killed in attack on the Butembo Hospital. Available: https://www.who.int/news-room/detail/19-04-2019-whoebola-responder-killed-in-attack-on-the-butembo-hospital

18 United Nations. Armed groups kill Ebola health workers in eastern DR Congo. Available: https://news.un.org/en/story/2019/11/ 1052421

19 Dyer O. MSF suspends Congo Ebola effort after deadly clinic attacks. BMJ 2019;364:I1010.

20 Nguyen V-K. An epidemic of Suspicion - Ebola and violence in the DRC. N Engl J Med 2019;380:1298-9.

21 Carrión Martín Al, Derrough T, Honomou P, et al. Social and cultural factors behind community resistance during an Ebola outbreak in a village of the Guinean forest region, February 2015: a field experience. Int Health 2016;8:227-9.

22 Elston JWT, Cartwright C, Ndumbi P, et al. The health impact of the 2014-15 Ebola outbreak. Public Health 2017;143:60-70.

23 Mukanga D, Namusisi O, Gitta SN, et al. Field Epidemiology Training Programmes in Africa - Where are the Graduates? Hum Resour Health 2010;8:18.

24 Moon S, Leigh J, Woskie L, et al. Post-Ebola reforms: ample analysis, inadequate action. BMJ 2017;356:j280. 